\title{
El acusador privado y el principio de igualdad de armas: una crítica al ordenamiento jurídico colombiano ${ }^{1}$
}

\author{
The private accuser and the principle of equality \\ of arms: a critique of Colombia's legal system
}

\author{
Miguel Díez Rugeles \\ Magíster en Derecho, Doctor en Filosofía \\ Especialista en Derecho Penal \\ Universidad Pontificia Bolivariana, Medellín - Colombia \\ Correo electrónico: miguel.diez@upb.edu.co \\ https://orcid.org/0000-0003-4663-7317 \\ Luis Felipe Vivares Porras \\ Doctor en Filosofía, Magíster en Derecho Procesal \\ Universidad Pontificia Bolivariana, Medellín - Colombia \\ Correo electrónico: luis.vivares@upb.edu.co \\ https://orcid.org/0000-0003-2954-5613
}

\section{Resumen:}

La ley 1826 de 2017 (ley 1826, 2017) introduce dos instituciones novedosas en nuestro ordenamiento jurídico: el procedimiento abreviado y el acusador privado. Esta última institución permite al representante de la víctima transformarse de interviniente a parte procesal, esto supone

1 Este trabajo es resultado de un proceso investigativo desarrollado como consecuencia del proyecto de investigación Imputación y Sociedad, adscrito al Grupo de Investigación en Sistema y Control Penal de la Universidad Pontificia Bolivariana. 
cambios en las condiciones jurídicas iniciales que impactan necesariamente a su contraparte: el acusado. Este impacto se advierte preponderantemente en relación con el llamado principio de la igualdad de armas. Interrogantes frente a la igualdad de condiciones entre las partes del proceso penal surgen frente a instituciones como: el principio de objetividad en la investigación, el descubrimiento probatorio, la carga de la prueba, los actos de investigación y los controles de estos últimos. Lo que pretendemos con este escrito es responder si, en el marco del procedimiento penal abreviado con presencia de acusador privado, la defensa del acusado puede solicitar, tal y como se le permite a su adversario procesal, la realización de actos complejos de investigación, conforme a la estructura del proceso penal colombiano y a los principios que lo orientan. Así, estaríamos contribuyendo a la discusión sobre las facultades investigativas de las partes en el proceso penal colombiano que interesa a académicos; pero también a los operadores del sistema penal.

\section{Palabras clave}

Acusador privado, igualdad de armas, actos complejos de investigación, procedimiento penal abreviado, principio de igualdad.

\section{Abstract}

The Ley 1826 de 2017 (Law 1826 of 2017) introduces two novel institutions to our legal system: the abbreviated procedure and the private accuser. This last institution allows the victim's representative to shift from intervening party to procedural part, this supposes changes on the initial legal conditions that necessarily impact his counterpart: the accused. This impact is predominantly noticeable when regarding the principle of equality of arms. Questions regarding the equality of conditions between the parties to a criminal trial arise before institutions such as the principle of objectivity in the investigation, the discovery of evidence, the burden of proof, the acts of investigation, and the controls of the latter. This paper intends to answer if within the framework of the abbreviated criminal procedure with the presence of a private accuser, the defense can request, exactly as the counterpart is allowed, the execution of complex investigation acts, in accordance to the structure of the Colombian criminal process and the principles that guide it. Thus, a contribution regarding the investigative powers of the parties in the Colombian criminal process that interest academics would be made; but also, to the operators of the penal system.

\section{Key words}

Private accuser, equality of arms, complex acts of investigation, abbreviated criminal procedure, principle of equality.

\section{Cómo citar este artículo:}

Diez, M, \& Vivares, L. F. (2020). El acusador privado y el principio de igualdad de armas: una crítica al ordenamiento jurídico colombiano. Revista de la Facultad de Derecho y Ciencias Políticas, 50 (133), pp. 309-339.

doi: http://dx.doi.org/10.18566/rfdcp.v50n133.a04

Recibido: 19 de julio de 2019.

Aprobado: 04 de marzo de 2020. 


\section{Introducción}

El denominado procedimiento acusatorio ordinario, cuyo origen se encuentra en el texto original de la ley 906 de 2004 (Ley 906, 2004), trae consigo un marcado desequilibrio entre las partes: acusador y acusado en las fases investigativas del proceso. Esto no solo por el poderoso músculo institucional sobre el que se eleva la Fiscalía General de la Nación sino también — y este es el punto relevante- por los actos de investigación que puede desplegar el ente acusador, en comparación con los realizables por la parte acusada.

El principio de igualdad de armas, baluarte de la validez y justeza del proceso penal, según habituales discursos jurisprudenciales y doctrinales, funge como aparato crítico de una normativa que establece ventajas investigativas para facilitar la acusación: mientras se dificulta la labor de la defensa. Con todo, el panorama no es del todo desolador: el principio de igualdad de armas es un principio que, como cualquier otra norma de carácter principial, no basta por sí mismo, pues para lograr su objetivo de garantizar iguales posibilidades procesales a las partes, debe complementarse con otros principios como: el derecho de defensa, la dignidad humana, la presunción de inocencia y postulados como el in dubio pro reo para así integrar las garantías que establece nuestro ordenamiento jurídico en favor del procesado. Esto aun cuando puede afirmarse que los principios de la dignidad humana y del derecho de defensa son más amplios que el de igualdad de armas; a la vez que el fundamento de la presunción de inocencia y del in dubio pro reo no se encuentra en la igualdad de armas sino en las reglas generales de la experiencia, al enseñar que lo ordinario es que las personas no delincan y lo extraordinario es el delito, por tanto la inocencia se presume y el punible debe acreditarse (Dei Malatesta, 1964).

Sin embargo, al entrar en vigencia la ley 1826 de 2017 (ley 1826, 2017) se instituyó en Colombia un procedimiento penal abreviado y un novedoso sujeto procesal: el acusador privado. Merece la pena lanzar interrogantes que inquieran sobre la adecuación de estas nuevas instituciones con las exigencias de la igualdad de armas, concretamente en relación con las facultades investigativas de las partes. ¿Están en igualdad de condiciones el ente acusador y la parte acusada? ¿Puede la defensa solicitar la ejecución de actos de investigación complejos como puede hacerlo el acusador? ¿Respeta el procedimiento penal abreviado el principio de la igualdad de armas, derivación especial del principio constitucional de la igualdad en materia procesal penal? Preguntas distintas, desde luego, pero ligadas por un común denominador que 
salta a la vista. Si el principio de igualdad de armas es una norma rectora de las actuaciones procesales en materia penal, cabe preguntar si una expresión específica del proceso, que es el procedimiento abreviado con acusador privado, se adecua o no a tal directiva.

Sin duda, son preguntas relativas a un problema específico. Lo interesante es que de su reflexión y resolución es posible derivar conclusiones generales frente a la dinámica procesal penal colombiana. Si las partes de este proceso gozan de un real estado de igualdad, podrá concluirse que el proceso penal nacional, pese a sus múltiples inconvenientes, lucha por garantizar un principio de orden constitucional como es el de la igualdad. Si no es el caso, habrá que concluir que nuestra sistemática procesal sufre de patologías insalvables y que es menester intervenirlas de inmediato, aunque sea desde la muchas veces desoída academia universitaria.

Con el fin de arribar a una conclusión, nos concentraremos en ciertos puntos neurálgicos del problema propuesto como: la estructura de partes e intervinientes, el principio de igualdad de armas y el principio de objetividad en la investigación. Sólo a través de este trayecto argumentativo, el lector comprenderá el sentido de las conclusiones que cierran este trabajo.

\section{La ley 1826 de 2017 y sus novedades: el procedimiento abreviado y el acusador privado}

Con la entrada en vigencia de la ley 1826 de 2017 (Ley 1826, 2017) opera una importante transformación de la sistemática procesal penal colombiana. En primer lugar, respecto de los sujetos procesales se introduce la figura del acusador privado, en la que el representante de la víctima, luego de solicitar la mal llamada conversión ${ }^{2}$ de la acción penal y de obtener el aval de la Fiscalía en los casos previamente delimitados por nuestro legislador ${ }^{3}$, va a asumir la posición que en un principio le corresponde al ente acusador oficial y, en consecuencia, en ejercicio del derecho fundamental de acción

2 En rigor, la acción penal no se transforma, pues sigue siendo una acción pública cuyo ejercicio se le delega a un particular que ejercerá transitoriamente funciones públicas y, en ese sentido, responderá como servidor público por asimilación (Ley 599,2000, art. 20).

3 "Ha de decirse, por una parte, que la normatividad se ocupa de aquellos delitos que se estiman menos graves, según la elemental lectura de la enmienda constitucional. Para valorar la secundaria entidad de los comportamientos se acude al concepto de bien jurídico, tanto desde su entidad, como también según la escasa lesión que a éste se haya causado". (Guzmán, 2017, p. 198) 
formulará la pretensión punitiva. Con esta reforma, la víctima del delito pasa de ser un interviniente especial a parte procesal stricto sensu a través de su representante.

En segundo lugar, con respecto a la estructura procesal, de manera paralela al proceso ordinario contemplado en la ley 906 de 2004 (ley 906, 2004), se introduce un nuevo procedimiento que pretende recortar las etapas procesales. En este novedoso rito procedimental han desaparecido la audiencia de imputación y la audiencia de lectura de fallo, se han fusionado las audiencias de acusación y preparatoria y en aquellos casos en los que actúa el acusador privado, se ha prescindido del incidente de reparación integral, de tal forma que los perjuicios sufridos por la víctima del delito pasaron a formar parte del objeto del proceso, por lo que se definirán en la sentencia de fondo.

Esta reforma fue un desarrollo legislativo del acto legislativo 06 de $2011^{4}$ y busca superar la crisis que padece actualmente nuestro sistema penal acusatorio $^{5}$ reflejada, sobre todo, en la cantidad de procesos penales que se encuentran represados en manos de la Fiscalía General de la Nación.

Así, con las reformas introducidas se busca abrir dos vías de escape para descongestionar nuestro sistema de la siguiente manera: (I) al permitir que la Fiscalía se desprenda, al menos parcialmente, de los procesos penales en los que el acusador privado solicite la conversión de la acción penal, siempre que ello sea viable. (II) Al establecer un nuevo procedimiento penal abreviado en su estructura para un grupo específico de delitos.

Sólo el tiempo dirá si la reforma logrará su cometido. Por ahora, basta dejar constancia de una razonable preocupación: es posible que la reforma logre descongestionar en algún grado a la Fiscalía General de la Nación; pero esto puede traer consigo la congestión de los jueces, tanto de conocimiento como de garantías, que incluso antes de la reforma se encontraban sobrecargados en su trabajo.

$\overline{4 \quad \text { El acto legislativo } 06}$ de 2011 modificó el artículo 250 del Constitución Política (Cons, 1991, art. 250) adicionando un parágrafo segundo donde se dice que: "Atendiendo la naturaleza del bien jurídico o la menor lesividad de la conducta punible, el legislador podrá asignarle el ejercicio de la acción penal a la víctima o a otras autoridades distintas a la Fiscalía General de la Nación. En todo caso, la Fiscalía General de la Nación podrá actuar en forma preferente." "Sin embargo, la norma establece que las entidades públicas podrán ejercer la acción penal, pero no determinó cuáles y dejó esa labor para una futura regulación legislativa". (Guzmán, 2017, p. 207)

5 Para un estudio de estas dos figuras puede consultarse a Fiscalía General de la Nación (2017). 
Con todo, creemos que si algunos institutos jurídicos vigentes - entre los que se destaca el principio de oportunidad ${ }^{6}$ - se hubiesen aplicado con la frecuencia esperada por el legislador del 2004, no nos encontraríamos frente a una crisis de sistema, como la que hace poco forzó la introducción de la reforma contenida en la ley 1826 de 2017. Sin embargo, más allá de esta hipótesis, no nos queda más que hacerle frente a la crisis referida y estudiar la nueva reforma procesal, al dejar de lado la cuestión de si resulta o no adecuada frente al problema.

Por último, debe resaltarse que a la fecha la Corte Constitucional se ha pronunciado en dos ocasiones con respecto a la ley 1826 de 2017 (ley 1826, 2017) $\mathrm{y}$, por el momento, no se han evidenciado problemas de constitucionalidad que se deriven de la regulación allí contenida. Adicionalmente, las dos sentencias que se profirieron no se han ocupado de los actos de investigación.

Así, en la sentencia C-016 de 2018 (sentencia C-016 de 2018) la Corte se declaró inhibida por una inadecuada interpretación del parámetro de control de constitucional y en la sentencia C-225 de 2019 (sentencia C-225 de 2019) se abordó la cuestión relativa a la posibilidad de aplicar la ley de marras en forma retroactiva. Se concluyó que, incluso cuando ya se ha formulado imputación, la ley 1826 de 2017 (ley 1826, 2017) se puede aplicar por virtud del principio de favorabilidad.

\section{La estructura de partes e intervinientes en el proceso penal acusatorio}

El sistema penal acusatorio, introducido mediante la ley 906 de 2004 (ley 906, 2004), instaura un sistema procesal de partes. De manera consecuente, la estructura fundamental del procedimiento acusatorio involucraba a tres sujetos procesales: las partes, a saber, acusador, acusado y el juez como tercero supra partes, imparcial e independiente. En virtud del modelo acusatorio de procesamiento no puede existir en nuestro sistema un juicio sin acusación. En el marco del procedimiento ordinario, la acusación está a cargo de la Fiscalía General de la Nación?7 mientras que el juzgamiento le corresponde al juez

6 En nuestra opinión, el problema con esta institución es que su aplicación se ha condicionado al cumplimiento de un trámite excesivo.

7 "Cabe destacar que la figura del fiscal está ligada desde su nacimiento al principio acusatorio, según el cual no puede haber juicio sin acusación. Antiguamente, en el sistema llamado "acusatorio puro" no podía haber juicio sin la acusación del damnificado, de la víctima". (Binder, 2016, p. 323). 
de conocimiento ${ }^{8}$. Por su parte, la defensa opone resistencia a la acusación. De esta forma, las partes se enfrentan en el escenario agonal, adversarial, dialéctico que suministra el proceso, al presentar sus respectivas teorías del caso ${ }^{9}$ para que el juez decida a cuál de ellas adherir desde su imparcialidad e independencia.

Además, nótese que en nuestro sistema al lado de las partes existen otros sujetos procesales llamados intervinientes: el agente del Ministerio Público, la víctima, el representante de ella y el tercero civilmente responsable. Esto sucede sin que las partes dejen de ser los protagonistas del proceso penal y, cabe insistir en ello, sin que los intervinientes se conviertan necesariamente en partes. Cubrir bajo un misma rúbrica -intervinientes - sujetos procesales tan disímiles entre sí, no deja de ser una falacia conceptual con la que tropieza nuestro legislador. En este escrito nos centraremos especialmente en el papel que despliega el representante de la víctima al estar extraordinariamente legitimado en la causa para obrar como parte procesal acusadora. Nos limitamos a mencionar a los otros sujetos procesales, en espera de que se propicien ulteriores discusiones sobre los mismos, para buscar distinguirlos en términos teóricos y normativos.

La víctima en el proceso penal es aquella persona que se ha visto perjudicada, de manera directa o indirecta como consecuencia del delito. Esa víctima, en ejercicio de su derecho fundamental a la tutela jurisdiccional efectiva (que se concreta en este caso en la posibilidad de acceder a la administración de justicia y de exigir el ejercicio de la potestad jurisdiccional) va a acudir al proceso penal a través de un representante. Este puede ser un abogado en ejercicio o un estudiantes adscrito a un consultorio jurídico para hacer valer sus derechos a la verdad, a la justicia y a la reparación integral.

Sin embargo, la víctima ha adquirido un papel central en el derecho penal moderno ${ }^{10}$ y ello se ha visto reflejado en el proceso penal. Es por esto que

8 "El juez es un funcionario del Estado con poder para solucionar un litigio que otras personas Ilevan a su consideración. Por otra parte, no se trata de "cualquier solución", sino de aquella solución prevista por el ordenamiento jurídico." (Binder, 2016, p. 316)

9 "La teoría del caso es, por sobre todas las cosas, un punto de vista. [...] La teoría del caso es un ángulo desde el cual es posible ver toda la prueba: un sillón cómodo y mullido desde el cual apreciar la información que el juicio arroja, en términos tales que si el tribunal contempla el juicio desde ese sillón, llegará a las conclusiones que le estamos ofreciendo." (Baytelman y Duce, 2011, p. 88)

10 Por ello, no nos parece exagerado lo dicho por Silva (2011): "Ello provoca la consiguiente transformación también en el ámbito del Derecho penal objetivo (ius poenale): en concreto, se tiende a perder la visión de éste como instrumento de defensa de los ciudadanos frente a la intervención coactiva del Estado. Y, así, la concepción de la ley penal como Magna Charta de la 
ordenamientos jurídicos como el nuestro han dotado al representante de la víctima de amplias facultades dentro del proceso penal ${ }^{11}$ : el derecho a ser debidamente notificado, el derecho a aportar elementos en la investigación del órgano acusador, el derecho a solicitar medidas de aseguramiento cuando la Fiscalía no lo hace, el derecho a descubrir elementos cognoscitivos, el derecho a solicitar medios de prueba, el derecho a alegar en la conclusión del juicio oral, el derecho a conocer los preacuerdos que se celebran entre Fiscalía y el acusado, el derecho a controvertir la aplicación del principio de oportunidad ante el juez de control de garantías, el derecho a aportar elementos cognoscitivos para oponerse a la solicitud de preclusión del fiscal, el derecho a pronunciarse sobre las solicitudes probatorias de las partes, el derecho a realizar observaciones al escrito de acusación, el derecho a solicitar el desarchivo de las diligencias, el derecho a impugnar, el derecho al restablecimiento de los derechos afectados, el derecho a solicitar medidas cautelares o de protección, etcétera.

No obstante, en muchos casos las facultades que le han sido reconocidas al representante de la víctima resultan insuficientes para satisfacer los intereses de esta última y, en particular, sus derechos a la verdad, a la justicia y a la reparación integral. Es allí donde nuestro legislador ha visto, más que un problema, una oportunidad. Por vía de la ley 1826 de 2017 (ley 1826, 2017) se reviste a la víctima de la posibilidad de subrogar al acusador oficial, mediando la previa autorización de este, a través de la figura de la conversión de la acción penal. Así, la víctima actúa a través de su representante, quien en estricto cumplimiento de una función pública que se le ha delegado especialmente para el caso en cuestión, ejerce la acción penal no sólo mediante los actos instructorios correspondientes sino también al formular la pretensión

víctima aparece junto a la clásica de la Magna Charta del delincuente; ello, si es que ésta no cede la prioridad a aquella." (Silva Sánchez, 2011, pp. 47-48). En un sentido similar se expresa Hassemer (1999): "la víctima aparece no ya como la simple figura de papel que encarna desde el punto de vista sistemático la lesión del bien jurídico, sino como una persona viva (alguien de carne y hueso) con cuyos legítimos intereses ha de contar, también desde el punto de vista sistemático, la teoría de los fines de la pena" (Hassemer, 1999, p. 110).

11 En este punto, la labor del legislador se ha visto ampliamente complementada por las decisiones de nuestras Altas Cortes. En particular véase la sentencia C-209 de 2007 (sentencia C-209 de 2007) de la Corte Constitucional. Por ello afirma Guzmán (2017): "Fue labor de la Corte Constitucional darle un estatus de interviniente especial a la víctima. Así, frente a las decisiones en las que hay disposición del ejercicio de la acción penal, se facultó a la víctima a oponerse o, por lo menos, a ser escuchada, como cuando se adopta el archivo, la inadmisión de la denuncia, los preacuerdos, la preclusión y el principio de oportunidad. También se le posibilitó su participación, aunque con restricciones, en el debate probatorio, al punto de tener la opción de solicitar medios de conocimiento a practicar durante el juicio. Puede la víctima, además, pedir al juez con función de control de garantías que se imponga medida de aseguramiento, en caso de que el fiscal no lo haga". (Guzmán, 2017, p. 195-196) 
punitiva ante la judicatura penal. La víctima pasa de interviniente a parte y su representante pasa de apoderado a servidor público por asimilación. En justa armonía con lo antedicho, la propia Fiscalía General de la Nación en la resolución 2417 de 2017 señala que "en los casos en que se autorice la conversión de la acción penal de pública a privada, el acusador privado debe relevar de manera completa a las autoridades públicas en sus funciones de investigar, acusar y probar en juicio” (resolución 2417 de 2017).

Por consiguiente, se puede ver todo un progreso en relación con la participación de la víctima en el proceso penal colombiano, el punto más alto son las facultades que le confiere la ley 1826(ley 1826, 2017). Al respecto, Matusan (2013) afirmó hace algunos años lo siguiente:

La participación de la víctima dentro del proceso penal ha tenido una progresividad de enormes magnitudes, pues además de las facultades otorgadas por la Ley 906 de 2004 y la ampliación de las mismas realizadas por vía jurisprudencial, debe sumarse la reciente modificación de la Constitución que incorporó la posibilidad de ejercer la precitada acción por parte de las víctimas, "desplazando" así al Fiscal mismo. (Matusan, 2013, p. 192)

\section{Principio de igualdad de armas}

Como en todo nuestro ordenamiento jurídico en materia penal, el principio de igualdad tiene una importancia radical. Dicho principio, en su concepción tradicional, nos dice que al igual se le debe tratar como igual y al desigual como desigual. En consecuencia, este principio se podrá vulnerar por dos vías: (I) al tratar al igual como desigual o (II) al tratar al desigual como igual.

Aún conservando su autonomía y validez en razón de su naturaleza constitucional, debe advertirse que del principio de la igualdad se derivan otros principios, quizá no explicitados por el constituyente; pero reconocidos por la doctrina y la jurisprudencia. En el campo procesal penal, del principio constitucional tratado se deriva el llamado principio de igualdad ${ }^{12}$ de armas

12 Por supuesto, esto sin dejar de reconocer el estrecho vínculo que existe entre el principio de igualdad de armas y otros principios como el derecho de defensa o el de la dignidad humana. De esta forma, la facultad del procesado de desarrollar su propia investigación le garantiza el derecho a una defensa técnica y proactiva; pero al mismo tiempo, le permite al procesado trazarse su propio destino en el contexto del proceso penal, a través de una investigación propositiva coordinada por su abogado. 
que, en términos ultra-sintéticos, ordena que el ente acusador y el acusado se encuentren en una misma posición procesal, para que ambas merezcan una misma disciplina jurídica, tanto en lo que se refiere a cargas y deberes como al tratarse de los derechos y potestades que otorga la ley con ocasión de las causas penales. En consonancia con estas afirmaciones ha dicho la Corte Constitucional:

Algunos doctrinantes y la propia Fiscalía General de la Nación hacen referencia a él como el principio de 'igualdad de armas', queriendo indicar con ello que, en el marco del proceso penal, las partes enfrentadas, esto es, la Fiscalía y la defensa, deben estar en posibilidad de acudir ante el juez con las mismas herramientas de persuasión, los mismos elementos de convicción, sin privilegios ni desventajas, a fin de convencerlo de sus pretensiones procesales. El Tribunal de Defensa de la Competencia Español (Resolución 240), ha establecido, por ejemplo, que el principio de igualdad de armas "exige que se conceda el mismo tratamiento a las partes que intervengan en el expediente" (Corte Constitucional, sentencia C-1194 de 2005).

Además, en el nuevo proceso penal se realiza una distribución de cargas procesales, pues el imputado y su defensor no tendrán que limitar su actuación a contender la acusación formulada en su contra, sino que han de ser diligentes en aportar elementos de juicio que sustenten su teoría del caso y confronten la versión del ente acusador, trabándose así una verdadera contención en la que se hace indispensable asegurar a los enfrentados equilibrio e igualdad de oportunidades sin desfigurar, claro está, el perfil constitucionalmente asignado a cada una de las partes. Con tal fin, se incorporó el principio de "igualdad de armas" o "igualdad de posiciones" que, como lo ha señalado esta Corte, constituye una de las características sobresalientes de los sistemas penales de tendencia acusatoria donde "los actores son contendores que se enfrentan ante un juez imparcial en un debate al que ambos deben entrar con las mismas herramientas de ataque y protección” (Corte Constitucional, sentencia C-186 de 2008).

Por su parte, la Corte Suprema de Justicia, en sentencia de casación del 27 de enero de 2016, con radicado 45790 y con ponencia de Gustavo Enrique Malo Fernández, señaló que es necesaria la perfecta igualdad de las partes en lo relativo a capacidades, poderes, contradicción, actos probatorios, entre otras facultades, para que el proceso se desarrolle en forma leal y con igualdad de armas. 
Resulta importante contextualizar con suficiencia al lector, identificar las distintas fuentes conceptuales y dogmáticas de las cuales ha derivado el principio en mención. Al respecto, parece conveniente comenzar por el inicio, esto es, por el procesalismo clásico en cuya cima, por méritos que lo distinguen con justicia de otros importantes pensadores, está Carnelutti (1971), dice así:

La verdad es que si el desdoblamiento [...] entre el juez y el ministerio público [léase: órgano acusador, fiscalía] o sea entre la jurisdicción y la acción, es necesario para la garantía de la imparcialidad y, con esta, para la justicia del castigo, no es, sin embargo, suficiente. Al final, el juez debe tomar una decisión; y decidir es elegir (...) Ciertamente, puesto que el juicio no conduce nunca a un resultado, del que el hombre prudente esté absolutamente seguro, e incluso tanto menos seguro está el hombre cuanto más prudente es, la decisión debe superar la duda; y la duda (dubium, de duo), implica dos soluciones. Es claro que tanto mejor está el juez en situación de elegir cuanto más claramente se le presentan delante las dos soluciones posibles. El peligro es que la duda no se le presente, no que él sea atormentado por ella. Ahora bien, el medio para proponerle la duda es el contradictorio; ayuda aquí la raíz común (duo) de dubium y duellum. Por eso, la separación del ministerio público [fiscalía] respecto del juez, esto es, de la acusación respecto del juicio, no basta para garantizar la justicia de este último. El ministerio público [fiscalía], si está solo junto al juez, es insuficiente. La acusación debe ser contrapesada y por eso integrada por la defensa. (Carnelutti, 1971, p. 43).

Con base en lo que podríamos llamar lógica del proceso, es decir, de las necesidades intrínsecas e inevitables del ejercicio del poder jurisdiccional por medio del proceso Carnelutti deriva el llamado principio del contradictorio o - como se dice con mayor resonancia en nuestro medio- principio de la bilateralidad de la audiencia. Una vez distinguida la función acusadora de la decisoria y, en consecuencia, ejercidas por sujetos procesales diferentes e independientes el uno del otro, resulta necesario que haya un órgano acusador denodadamente parcial frente a un juez decisor imparcial. Solo es posible hablar de un sujeto supra partes si se le confronta con sujetos inter partes, parcializados. Pero, por eso mismo, sólo será parcial la Fiscalía si en frente de ella, en su misma posición, a su misma altura y condición se halle un adversario, una real contraparte, que será el imputado-acusado acompañado por su defensor. Simbiosis que nuestro código de procesamiento penal llama elípticamente: la defensa. 
Por otro lado, parece necesario subrayar un argumento — desde luego discutible - formulado por el tratadista italiano en las líneas citadas. Al escoger un criticable pero sin duda razonable concepto de justicia, sostiene Carnelutti que la previa y activa participación de las partes eventualmente sujetas a una decisión jurisdiccional, es condición sine qua non de la justeza y equidad de la misma. Sólo si las partes coparticipan junto con el juez en la formulación del mandato contenido en la sentencia esta puede calificarse de justa.

¿En qué radica dicha participación? Nos parece que en este punto no es Carnelutti sino Calamandrei quien responde con mayor claridad y contundencia el interrogante formulado, al pronunciarse sobre lo que él llama principio de la demanda y de la bilateralidad de la acción:

La estructura del proceso con partes contrapuestas ("Parteprozess" lo llama la doctrina alemana), que se encuentra en todas las legislaciones modernas, no es sólo una natural consecuencia del principio de la demanda y de la bilateralidad de la acción, sino que es técnicamente el dispositivo psicológico más apropiado para garantizar, especialmente en la fase de cognición, la aplicación exacta de la ley y, en consecuencia, la satisfacción del interés público de la justicia. El contradictorio entre las partes, aunque determinado por el contraste de intereses individuales, sirve siempre para multiplicar en el juez los medios de indagación y de control en orden de la declaración de certeza de la verdad: la cual no aparece nunca en toda su entereza si se la examina sólo desde un punto de vista, sino que necesita, para ser plenamente conocida, ser iluminada desde distintos puntos de enfoque, y con provecho tanto mayor, cuanto más distantes sean entre sí y dispares. La existencia de un contraste polémico entre los contradictores permite al juez reconstruir, gracias a ellos, la verdad en tres dimensiones; sino fuesen dos las partes, el juez no podría ser imparcial.

[...] Una confirmación de lo que decimos, puede encontrarse también en la estructura del proceso penal, en el que la ley ha creado, frente al imputado, un órgano público encargado de ejercer el oficio de acusador [...] Este, aun no persiguiendo una finalidad distinta a la que persigue el juez (a saber, la observancia de la ley penal), y no pudiendo, por tanto, ser considerado en necesario contraste de intereses con el imputado (ya que también el Ministerio Público [Fiscalía] tiene interés en que el imputado inocente sea absuelto), figura, no obstante, procesalmente, como contradictor natural del acusado: esta contraposición de partes, que permite al juez mantenerse psicológicamente imparcial, por encima de la contienda, es una garantía 
esencial de la justicia en virtud de la cual el moderno proceso penal acusatorio constituye un progreso sobre el proceso penal inquisitorio de otros tiempos, en el cual el juez, acumulando en sí la función de acusador, se encontraba siempre con que, aun contra su voluntad, era perseguidor parcial del imputado sometido a su juicio; es decir, que venía a ser, según la feliz expresión de Beccaria, “enemigo del reo” (Calamandrei, 1973, pp. 294 - 296).

Las dos partes contrapuestas: acusador y acusado, inculpador y adversario, son necesarias para garantizar, no sólo jurídica sino también psicológicamente, el estado imparcial que se exige del juez. Sólo sirviéndose de la acción y reacción desplegadas por ambas partes que realizan sobre los hechos acontecidos y las normas jurídicas idóneas para regularlos, el juez puede llegar a una decisión justa, principalmente porque será una decisión basada en un conocimiento real y confiable de los hechos. Mientras más dispares y contradictorias sean las posiciones proyectadas por las partes del proceso penal, mayor será el espectro de indagación que deberá abordar el juez; pero también mayores serán los elementos de juicio con los que contará para pronunciarse sobre la efectiva ocurrencia de un acontecimiento con relevancia jurídico-penal. No sobra recordar a Taruffo (2006), que si bien es un autor que no duda en criticar el modelo adversarial y contradictorio del proceso, es categórico al afirmar que:

Ninguna decisión se puede definir como justa si se basa en hechos equivocados, o sea en la reconstrucción errónea o falsa de las circunstancias que son la base de la controversia. Si los hechos no se comprueban de manera racional y verídica, cualquier aplicación de cualquier norma a ese caso particular resulta privada de fundamento, y por tanto arbitraria. (Taruffo, 2006, p. 204).

Con razón Calamandrei (1973) resalta que el contradictorio no es una condición exclusiva del proceso civil. Si bien es cierto que entre las partes procesales del proceso penal no subyace un conflicto de intereses - lo que sí ocurre, por el contrario, en el proceso civil—, es cierto que los beneficios que se obtienen al estimular y fortalecer la contradicción entre las partes son necesarios en cualquier tipo de proceso, sin importar las peculiaridades que el derecho material que se aplicará por cuenta de la sentencia supongan para la constitución y dinámica de los procesos. Dicho de otra forma: sin que con ello se desconozcan diferencias importantes entre el proceso penal y el civil, el arreglo dialéctico y adversarial que brota, casi de manera natural en el campo civil, debe implementarse en el proceso penal, pues el contradictorio es la garantía de la imparcialidad del juez, de la justicia y de la veracidad de sus sentencias. 
Empero, al analizar el concepto de contradictorio y perfilarlo como antecedente inmediato y fundante del principio de igualdad de armas, debe anotarse sumariamente el principal vicio que se le imputa a la organización adversarial de las formas procesales: la facilidad con la que se puede mentir y, en consecuencia, afectar la decisión del juez. En una oportunidad anterior, uno de los autores del presente escrito manifestó:

Con todo, los críticos del contradictorio ponen sobre relieve la activa participación de los abogados de las partes como motivo de preocupación para el correcto conocimiento de los hechos en el proceso [...] dicen los críticos, no es posible ver en el contradictorio una herramienta para el conocimiento de la verdad, cuando los que efectúan los actos del contradictorio son los abogados, personas distintas a las partes, reales protagonistas de la experiencia vital cuya reconstrucción es necesaria dentro del proceso. [...] simplificando la crítica hasta su más básica expresión sin sacrificar su sentido, tenemos que algunos críticos no confían en el contradictorio como instrumento epistémico idóneo, por la facilidad con la que se miente en ejercicio del mismo. El problema no es el contradictorio: es la mentira. (Vivares Porras, 2017, p. 144)

Es cierto, se frustra la función garante del contradictorio de proporcionar un conocimiento cierto de los hechos y de propiciar una decisión justa, si los protagonistas principales del proceso - los abogados- nos aprovechamos indebidamente de este y lo convertimos en un burdo instrumento legitimador de mentiras. Pero no es un problema del contradictorio, porque tampoco es un problema propio del derecho procesal. Es más: no es un problema jurídico. Es un problema ético. Por más mecanismos, remedios y sanciones que invente el Derecho para evitar la mentira en el marco de los procesos, esta estará siempre presente si los hombres que actúan en ellos, en especial los abogados, carecen de límites éticos que les impidan falsear la realidad ${ }^{13}$.

13 Al respecto, dice Vivares: "[...]el contradictorio funciona, es decir, hace visible la verdad, si los abogados entienden que, además de servir a los intereses de sus clientes, están comprometidos con el Estado en su interés institucional de hacer justicia en el caso concreto. Si, por el contrario, los abogados malinterpretan su cometido y falsean la verdad, así sea con el ánimo de proteger los derechos de sus representados, no opera, así como la función de la historia de forjar vínculos de comprensión entre los hombres del presente y los hombre del pasado se frustra, si el historiador, en lugar de buscar comprender al otro, adultera su realidad, falsea su historia, en pro de intereses particulares, loables o no" (Vivares, 2017, p. 145). 
En fin, el contradictorio o bilateralidad de la audiencia es el desarrollo procesal inmediato del principio constitucional de la igualdad. Ahora bien, la expresión "igualdad de armas" — proveniente originalmente de la literatura clásica del derecho anglosajón- no puede considerarse como un simple sinónimo del principio de la igualdad y del principio del contradictorio. Nos referimos a conceptos interrelacionados e interdependientes; mas no a simples giros sinonímicos. El principio de igualdad de armas, como se colige de su nombre, supone que las partes del proceso — entendido como un combategozan de las mismas posibilidades de ataque y respuesta.

Al considerar la jurisprudencia del Tribunal Europeo de Derechos Humanos, Antonio Cassese (2008) hace la siguiente aclaración al respecto:

First, there is a concept developed in the case law of the European Court of Human Rights over the years. It implies that the accused may not be put at a serious procedural disadvantage with respect to the prosecutor. This applies to the accused only: human rights treaties do not grant the prosecutor the right to be put on a par with the defence. On the other hand, human rights treaties do not forbid, and sometimes even require, the accused to be put in a 'better' or more advantageous position than the prosecution in order to preserve an overall balance in the proceedings (the prosecutor normally being better equipped than the defence for the collection of evidence). Secondly, equality of parties is an essential ingredient of the adversarial structure of proceedings, based on the notion of the trial as a contest between two parties. Under this approach, it is indispensable for both parties to the proceedings to have the same rights; otherwise, there is no fair fight between the two 'contestants', and the spectators will not be convinced by the outcome. Here fairness works both ways and therefore also the prosecutor is entitled not to be put in a disadvantageous position. Similar worries do not exist in inquisitorial systems of justice, where proceedings are conceived of as an 'official inquiry. (Cassese, 2008, p. 384 - 385)

Varias son las conclusiones que se perfilan de estas líneas. En primer lugar, el principio de igualdad de armas no sólo tiene un origen conceptual rastreable en la lógica misma del proceso y en la necesidad de garantizar decisiones justas. También la tutela jurídica de los Derechos Humanos justifica el reconocimiento institucional del principio estudiado. Desde otra perspectiva, la igualdad de armas, además de ser una garantía para la satisfacción de necesidades intrínsecas del proceso, también funge como instrumento amparador de Derechos Humanos que pueden entrar en tensión con otros derechos, privilegios y potestades que se hacen presentes en la dinámica procesal. 
En segundo lugar, cabe resaltar una diferenciación de tratamiento por parte del Tribunal Europeo de Derechos Humanos en relación con el principio que venimos mencionando: de lo que se trata es evitarle posiciones de desventaja al acusado respecto de la parte acusadora; pero la relación contraria no es válida. Según el autor, el Tribunal en mención ordena -incluso en contravía de otras posiciones teóricas más difundidas y, quizá, igual de respetables- en poner al defendido en una posición más ventajosa que el ente acusador, si así se garantiza el balance en las situaciones procesales en las que se encuentran las partes. En palabras más sencillas, la igualdad de armas es un principio que tutela los intereses de la parte acusada, no de la parte acusadora, que por su carácter institucional, goza de una natural posición de superioridad respecto de su contraparte.

En tercer lugar, el principio de igualdad de armas realza y acentúa la naturaleza dispositiva del proceso penal. Un proceso será dispositivo si las partes tienen la posibilidad de combatir en igualdad de condiciones ante un tercero imparcial. Como dice el profesor español Juan Montero Aroca: "hay que reducir el Ministerio Fiscal a la condición de parte y evitar que existan medios distintos para formular la acusación y sostener la defensa" (Montero, Gómez, Montón y Barona, 2003, p. 329). El órgano acusador debe carecer de cualquier tratamiento especial por su estatus oficial; en el proceso ha de ser una parte más, un mortal cualquiera, no un ente oficial superpuesto al acusado por cuenta del aparato estatal que lo sostiene.

En el ámbito nacional, el principio de igualdad de armas ha sido reconocido principalmente en la jurisprudencia de la Corte Constitucional, se debe resaltar el trabajo realizado por el Tribunal Constitucional en las sentencias C-616/14, C-127/11 y C-186/08. Al respecto, la doctrina nacional ha indicado que:

Por su parte, el otro extremo de la contienda dialéctica, La Defensa, tiene como su principal principio el de la igualdad de partes o, como se le conoce, "igualdad de armas"; el cual se traduce en tener las mismas oportunidades de acceso a los elementos de conocimiento que su contrincante, la Fiscalía o, en este caso, el acusador privado. Con ello se permite que el ejercicio del derecho de defensa sea no solo un discurso retórico sino también propositiva y afirmativa, con aporte probatorio de lo que se pretende refutar o invocar. (Londoño,2017, p. 121) 
Por lo dicho, este principio tiene gran relevancia en materia de actos de investigación ${ }^{14}$, que como lo indicamos en la introducción, consisten en el objeto de estudio principal en este texto. Los actos de investigación se pueden definir como aquellas actuaciones que se realizan con miras a recolectar piezas cognoscitivas, esto es, elementos materiales probatorios, evidencia física, información y, en general, cualquier elemento de juicio. Ahora bien, el principio de igualdad de armas no se basta a sí mismo, al considerar la diferencia que existe entre el músculo investigativo con el que cuenta la Fiscalía General de la Nación y los pocos recursos con los que cuentan normalmente los defensores, ya sean públicos o privados. Por esto, se hace necesario integrar este principio con otros, como son el principio de presunción de inocencia (que incluye el in dubio pro reo), el principio de contradicción en sentido amplio (que comprende la controversia y la contradicción en sentido estricto), el principio de no autoincriminación ${ }^{15}$, entre otros.

Adicionalmente, a fin de garantizar este principio, el legislador ha regulado lo atinente a los actos de investigación que pueden desarrollar o ejecutar las partes en el proceso penal. En relación con la Fiscalía, encontramos que esta puede desarrollar todos y cada uno de los actos de investigación que se encuentran contemplados en nuestro Código de Procedimiento Penal. De un lado, porque la Fiscalía General de la Nación tiene a su cargo la facultad de acusar, como consecuencia del principio de la presunción de inocencia, es por esto que asume la carga de probar la responsabilidad del acusado más allá de toda duda razonable. Así, para dar cumplimiento a la carga probatoria que se le impone, la Fiscalía debe contar con un amplio abanico de actos de investigación que le permitan pertrecharse de elementos cognoscitivos suficientes para acusar y posteriormente solicitar una condena en juicio oral. Por otro lado, porque la Fiscalía en su investigación se guía por el principio de objetividad, de tal manera que, al encontrar elementos de conocimiento favorables al procesado, se los deberá descubrir a la defensa.

En principio, si el ente acusador pretende ejecutar actos de investigación que afectan derechos o garantías fundamentales, la regla general es que dichos actos deben someterse a la revisión previa y posterior del juez de

14 "Como se anticipó en páginas precedentes, uno de los cambios más importantes que se pudieron dar, al pasar de un sistema inquisitivo a uno adversarial, fue la institución del principio de "la igualdad de armas", que no era otra cosa que la afirmación de la posibilidad de ejercer el derecho de defensa sin más limitaciones que lo establecido en la ley, a través de los actos de investigación propios, es decir, sin los obstáculos que suponía el ruego de justicia ante fiscales y jueces". (Londoño, 2017, p. 139)

Que sería más bien un privilegio, es decir, una libertad reconocida y protegida por el derecho. 
control de garantías. Sin embargo, merece la pena detenernos en algunos actos de investigación que, aunque intervienen derechos fundamentales, en virtud de lo dispuesto en el artículo 250 de la Constitución (Const., 1991, art. 250) pueden ordenarse por la Fiscalía General de la Nación sin que medie autorización previa del juez de control de garantías, aun cuando los resultados de los mismos deban someterse a control posterior ante dicho juez:

Artículo 250. La Fiscalía General de la Nación está obligada a adelantar el ejercicio de la acción penal y realizar la investigación de los hechos que revistan las características de un delito que lleguen a su conocimiento por medio de denuncia, petición especial, querella o de oficio, siempre y cuando medien suficientes motivos y circunstancias fácticas que indiquen la posible existencia del mismo. No podrá, en consecuencia, suspender, interrumpir, ni renunciar a la persecución penal, salvo en los casos que establezca la ley para la aplicación del principio de oportunidad regulado dentro del marco de la política criminal del Estado, el cual estará sometido al control de legalidad por parte del juez que ejerza las funciones de control de garantías. Se exceptúan los delitos cometidos por Miembros de la Fuerza Pública en servicio activo y en relación con el mismo servicio.

En ejercicio de sus funciones la Fiscalía General de la Nación, deberá:

[...]

2. Adelantar registros, allanamientos, incautaciones e interceptaciones de comunicaciones. En estos eventos el juez que ejerza las funciones de control de garantías efectuará el control posterior respectivo, a más tardar dentro de las treinta y seis (36) horas siguientes, al solo efecto de determinar su validez (Constitución Política de Colombia,1991, art. 250).

Por lo dicho, pese a que son actos de investigación que afectan derechos fundamentales, ni el registro y allanamiento, ni las incautaciones, ni las interceptaciones de comunicaciones en sentido amplio están sujetos al control previo del juez de control de garantías.

Por otra parte, la defensa tiene un ámbito de investigación ${ }^{16}$ restringido, si se compara con el de la Fiscalía, pues en virtud de lo dispuesto en el artículo 267 (Código de Procedimiento Penal, 2004, art. 267) y siguientes del Código de

16 Las facultades investigativas de la defensa se encuentran íntimamente vinculadas con el derecho de defensa: "A este derecho es inherente la facultad consagrada en el citado artículo 267 CPP, porque valiéndose de la potestad de recaudar evidencias, material probatorio y su consecuente incorporación al proceso, el indiciado, imputado o acusado puede direccionar la forma de ejercer el derecho a defenderse". (Bernal y Montealegre, 2013, p. 197) 
Procedimiento Penal ${ }^{17}$, podrá ejecutar los siguientes actos investigativos que, vale agregar, no suponen afectación alguna de los derechos fundamentales de los terceros:

a. Recolección empírica de elementos materiales probatorios o evidencia física (Código de Procedimiento Penal, 2004, art. 268).

b. Análisis de elementos materiales probatorios o evidencia física por parte de peritos públicos o privados (Código de Procedimiento Penal, 2004, art. 270).

c. Realización de entrevistas (Código de Procedimiento Penal, 2004, art. 271).

d. Realización de declaraciones juradas. (Código de Procedimiento Penal, 2004, art. 272)

Por otra parte, pensamos que también la defensa puede adelantar actos de investigación que pueden afectar derechos fundamentales. Un ejemplo indiscutible es la posibilidad de realizar búsquedas selectivas en bases de datos. En relación con este acto de investigación, que puede afectar los derechos fundamentales a la intimidad y al habeas data, pensamos que en aplicación del principio de igualdad de armas y teniendo en cuenta que puede ser ejecutado por particulares, a través de solicitudes fundamentadas en la autorización del juez de control de garantías, no hay por qué negarle al acusado la posibilidad de ejecutarlo, siempre que los resultados del acto se sometan a control posterior por parte del juez de control de garantías. Así lo ha definido la Corte Suprema de Justicia (2017) en decisión de tutela STP6135-2017, con ponencia de la magistrada Patricia Salazar Cuéllar.

Lo cierto es que el principio de igualdad de armas aplica para las partes del proceso penal, esto es, para la Fiscalía y el acusado; pero no para los intervinientes: ministerio público, representante de la víctima o tercero civilmente responsable.

No obstante, debe señalarse que, como se vio, a la víctima se le han reconocido atribuciones que se derivan de sus derechos a la verdad, la justicia y la reparación integral, que implican la posibilidad de solicitar pruebas ante el juez de conocimiento y, por ende, de investigar por su cuenta con miras a obtenerlas.

Por tanto, si las partes tienen como respaldo para su investigación el principio de igualdad de armas, la víctima tendrá como respaldo su derecho

17 Ley 906 de 2004. 
fundamental de acceso a la administración de justicia. Adviértase, además, que esta última circunstancia puede producir un desequilibrio material en la igualdad que se predica entre acusador y acusado, pues la defensa podrá encontrarse con dos investigaciones: la del ente acusador y la del particular perjudicado, aun cuando la investigación de este no tenga el mismo alcance.

Por lo dicho, Londoño ha manifestado con gran acierto: "la actividad investigativa de los particulares se abre paso, para el hallazgo de los elementos de conocimiento y las solicitudes probatorias en la etapa de juicio, dejando de ser la búsqueda de la verdad uno monopolio del estado”. (Londoño, 2017, p. 141).

Pero a esto debe sumarse que, en los casos en los que proceda la conversión de la acción penal, el acusador privado se convertirá en una auténtica parte procesal y, en rigor, la Fiscalía dejará de serlo. Por consiguiente, el principio de igualdad de armas, en los casos en los que aparezca el acusador privado, se predicará de este último y del acusado; mas no de la Fiscalía. En consecuencia, para analizar el mencionado principio a la luz de la ley 1826 (ley 1826, 2017), debemos atender a las facultades investigativas que le han sido conferidas al acusador privado.

\section{Principio de objetividad en la investigación}

El artículo 250 de la Constitución (Const., 1991, art. 250) consagra el principio de investigación objetiva. Dicho principio dice que si bien la Fiscalía sólo debe investigar aquello que le es favorable a su teoría del caso, si encuentra algo que le resulta favorable al procesado, se lo deberá descubrir a la defensa en el escrito de acusación ${ }^{18}$. No se confunda lo anterior con el principio de investigación integral, institución de la ley 600 del año 2000 (ley 600, 2000), que ordenaba a la Fiscalía investigar todo, esto es, tanto lo favorable como lo desfavorable en relación con el procesado.

Por otro lado, debe tenerse en cuenta la sanción contemplada por nuestro ordenamiento jurídico para el caso en el que se omite descubrir un elemento cognoscitivo, una prueba anticipada o los datos de un testigo. Dicha sanción

18 “Artículo 250, Constitución Política, 1991. [...] En el evento de presentarse escrito de acusación, el Fiscal General o sus delegados deberán suministrar, por conducto del juez de conocimiento, todos los elementos probatorios e informaciones de que tenga noticia incluidos los que le sean favorables al procesado". 
es el rechazo del elemento, por lo que el mismo no podrá llevarse al juicio oral. Sanción que resulta problemática, si se tiene en cuenta que es posible que no se descubra el elemento, la prueba anticipada o los datos del testigo, precisamente porque no se quiera llevarlos al juicio.

Pues bien, conforme a la ley 1826 de 2017 (ley 1826, 2017) en algunos eventos previstos por la ley y previa solicitud de la víctima a través de su representante, el acusador privado va a ejercer la función acusadora que en principio le pertenece al fiscal, debemos preguntarnos si éste acusador se encuentra vinculado o no por el principio de objetividad en la investigación. Al considerar la naturaleza constitucional de la norma que impone el principio de objetividad, desde un plano constitucional no hay razones para sostener que la misma no le deba ser aplicable al acusador privado, pues este ha asumido el ejercicio de la acción penal y, en consecuencia, debe asumir los deberes y las cargas que se derivan de dicho ejercicio.

Sin embargo, encontramos que esto puede reñir con lo dispuesto en la ley 1123 de 2007(ley 1123, 2007), pues resulta evidente que el acusador privado debe ser leal con su cliente, es decir, con la víctima. Además, deben considerarse las consecuencias prácticas del incumplimiento de dicha norma, pues si se tiene en cuenta la sanción, esto es, el rechazo, el interés particular que representa el acusador privado y las obligaciones profesionales de este último, nos resulta difícil confiar en que este asumirá el principio de objetividad en su investigación. Sobre el interés particular que persigue la víctima en el proceso penal, resulta pertinente lo expuesto por Matusan Acuña:

La parcialidad en la que se encuentran las presuntas víctimas, aunada a la facultad de adelantar investigaciones, puede facilitar desafueros mayores. Rememórese que, cuando el ejercicio de la acción penal se encuentra en cabeza del ente acusador (Fiscalía), el funcionario judicial debe acatar el principio de objetividad, según el cual solamente puede adelantar investigaciones de conductas que efectivamente revistan las características de punibles y, con base en el mismo principio, solamente está facultado para imputar cargos ante el respectivo Juez de Garantías cuando del acopio de las evidencias e información legalmente obtenida puede deducirse razonablemente que existen suficientes elementos "probatorios" que permiten dar al traste con la presunción constitucional de inocencia. Es justamente esa objetividad la que permite que el fiscal archive las conductas que carecen de la necesaria tipicidad objetiva, solicite las correspondientes preclusiones o ejerza la discrecionalidad en el ejercicio de la acción, mediante la aplicación del principio de oportunidad. 
Contrario sensu la víctima, por las circunstancias propias que ameritan la acción, carece de toda objetividad, ya que como es natural el haberse visto afectada por la conducta desplegada por el sujeto activo parcializa su postura llegando incluso a convertir la persecución penal en un simple mecanismo de venganza. Incontables son los ejemplos que trae la historia respecto de abusos en el ejercicio de la Acción Privada consistentes en falsas imputaciones, recopilación de evidencias carentes de fiabilidad y adecuaciones típicas completamente inexactas. (Matusan Acuña, 2013, p. 194)

Así las cosas, se nos permitirá, por lo menos, dudar de la objetividad en la investigación que adelanta el Acusador Privado y esto debería traer consigo consecuencias importantes, pues una de las razones que justificaba el que la Fiscalía pudiera realizar la totalidad de los actos de investigación previstos por nuestro legislador era, según se vio, que esta debía observar el principio de objetividad en su investigación.

\section{Los actos de investigación según la ley 1826 de 2017}

En la ley 1826 de 2017 (ley 1826, 2017) encontramos dos artículos que se refieren a las facultades de investigación del acusador privado:

Artículo 34. La Ley 906 de 2004 tendrá un nuevo artículo 556, así: Artículo 556. Actos de investigación. El titular de la acción privada tendrá las mismas facultades de investigación que la defensa. El acusador privado no podrá ejecutar directamente los siguientes actos complejos de investigación: interceptación de comunicaciones, inspecciones corporales, registros y allanamientos, vigilancia y seguimiento de personas, vigilancia de cosas, entregas vigiladas, diligencias de agente encubierto, retención de correspondencia y recuperación de información producto de la transmisión de datos a través de las redes de comunicaciones.

Artículo 35. La Ley 906 de 2004 tendrá un nuevo artículo 557, así: Artículo 557. Apoyo investigativo. Cuando se autorice la conversión de la acción penal, la investigación y la acusación corresponden al acusador privado. Excepcionalmente, el acusador privado podrá solicitar autorización para la realización de actos complejos de investigación ante el juez de control de garantías, en este evento, el juez además de verificar el cumplimiento de los requisitos legales, valorará la urgencia y proporcionalidad del acto investigativo. De encontrarlo procedente, el Juez ordenará al Fiscal que 
autorizó la conversión de la acción penal o al que para el efecto se designe, que coordine su realización. La ejecución del acto complejo de investigación estará a cargo exclusivamente de la Fiscalía General de la Nación y deberá realizarse en los términos establecidos en la ley para cada caso. Culminada la labor el fiscal acudirá ante juez de garantías, en los términos de este Código, para realizar el control posterior correspondiente. Legalizado el acto, la evidencia recaudada y la información legalmente obtenida en la diligencia serán puestas a disposición del acusador privado respetando los protocolos de cadena de custodia. Parágrafo $1^{\circ}$. La información recaudada en el marco de los actos de investigación aquí descritos gozará de reserva. En consecuencia, el acusador privado no podrá divulgar la información a terceros ni utilizarla para fines diferentes al ejercicio de la acción penal, so pena de incurrir en alguna de las conductas previstas en el Código Penal. Parágrafo $2^{\circ}$. Si el acusador privado es sorprendido en actos de desviación de poder por el ejercicio de los actos de investigación se revertirá inmediatamente el ejercicio de la acción. Así mismo, se compulsarán las copias penales y disciplinarias correspondientes.

De la lectura de los citados artículos se deduce, sin lugar a dudas, que las facultades de investigación que se le entregan al acusador privado son bien distintas a las que originalmente le corresponden a la Fiscalía General de la Nación. Esto por lo siguiente: el fiscal, en su rol de parte acusadora, puede realizar la totalidad de los actos de investigación previstos por nuestro legislador. Como se vio, la regla general es que para la realización de actos de investigación que afecten derechos o garantías fundamentales la Fiscalía debe someterlos a los controles previos y posteriores por parte del juez de control de garantías. Sin embargo, por expresa disposición constitucional, en algunos de esos actos que afectan derechos o garantías fundamentales, bastará la orden previa de la Fiscalía y la revisión posterior del juez de control de garantías.

En el caso del acusador privado, sus facultades para la investigación no tienen el mismo alcance que las de la Fiscalía General de la Nación, al punto que en un principio se equiparan a las de la defensa ${ }^{19}$ (Ley 1826, 2017, art. 34). Adicionalmente, el acusador privado no puede realizar por su cuenta actos de

\footnotetext{
19 "Con esto en mente, la ley recientemente aprobada concede al acusador privado las mismas facultades que a la defensa durante la indagación e investigación, en los términos de los artículos 267 a 274 de la ley 906 de 2004. En concreto, se refiere a la posibilidad de obtener evidencias y preservarlas según los principio del sistema de cadena de custodia, con la facultad de acudir incluso a peritos oficiales, a la policía judicial o al Instituto Nacional de Medicina Legal para su examen". (Guzmán, 2017, p. 208)
} 
investigación que intervengan derechos o garantías fundamentales ${ }^{20} \mathrm{y}$, en caso de requerir la realización excepcional de dichos actos, deberá acudir al juez de control de garantías para su autorización (control previo), a la Fiscalía para su ejecución ${ }^{21}$ y, nuevamente, al juez de control de garantías para su control posterior (ley 1826, 2017, arts. 34 y 35).

Entendemos, en todo caso, que los actos de investigación complejos de los que habla la ley 1826 de 2017 son aquellos actos que intervienen derechos o garantías fundamentales y que, por lo mismo, no se reducen a los actos enumerados en el artículo 34 (ley 1826, 2017, art. 34) de la citada ley, dicha lista es enunciativa mas no taxativa. Aun cuando algunos autores no lo entiendan así22.

En todo caso, tanto en el control previo como en el control posterior, el juez de control de garantías deberá agotar el test de proporcionalidad en relación con el acto de investigación y con los resultados del mismo. Esto no constituye una novedad en nuestro sentir, pues dicho análisis se debería agotar en todos los casos en los que se limitan o se pretenden limitar derechos o garantías fundamentales.

Por otro lado, como ya lo advertimos, creemos que existe el riesgo de que el acusador privado no se guíe por el principio de objetividad en su investigación, por lo que, si en búsqueda de elementos materiales probatorios, evidencia

20 "El acusador privado tiene las mismas facultades investigativas que la defensa (Art. 34 Ley 1826 de 2017), pero no podrá realizar los siguientes actos complejos de investigación: Interceptación de comunicaciones, inspecciones corporales, registros y allanamientos, vigilancia y seguimiento de personas, vigilancia de cosas, entregas vigiladas, diligencias de agente encubierto, retención de correspondencia y recuperación de información producto de la transmisión de datos a través de redes de comunicación". (Saray, 2017, p. 1021)

21 "Por lo pronto, señala la normatividad que el acusador privado no podrá ejecutar directamente actos complejos de investigación como interceptación de comunicaciones, inspecciones corporales, registros y allanamientos, entregas vigiladas, diligencias de agente encubierto, retención de correspondencia y recuperación de información producto de la transmisión de datos. Esto traduce, según el artículo 557, en que será el fiscal que tenía la investigación o el que sea designado coordine la ejecución de ese acto investigativo". (Guzmán, 2017, p. 209)

22 "En conclusión, la propuesta legislativa expresamente impone una limitación al ejercicio investigativo de la acusación privada, estableciendo una categoría dentro de los actos de investigación, pero, al establecer un criterio para considerarlos como tal, determina un criterio subjetivo como lo es la grave afectación de derechos fundamentales. Esto quiere decir, se insiste, que deberá ser el juez, con la aplicación del test de proporcionalidad el que deba determinar el mayor o menor grado de afectación que se lograría con aquellos actos de investigación que no se consideraron por el legislador como de naturaleza compleja, ordenando dentro de su autorización todas las medidas necesarias para que el ejercicio de la acción penal no se desborde y se limite a la necesaria búsqueda de los elementos de conocimiento que requiere el actor privado". (Londoño, 2017, p. 147-148) 
física o información legalmente obtenida que le sea favorable a su teoría del caso se encuentra con elementos que beneficien al procesado, posiblemente no se los descubrirá al acusado.

Posiblemente, la duda que se genera respecto de la objetividad en la investigación del acusador privado fue precisamente la razón que llevó a nuestro legislador a limitar sus facultades en la investigación. Recordemos que uno de los argumentos que justifica el que la Fiscalía pueda realizar la totalidad de los actos de investigación es el carácter objetivo de su investigación.

Ahora bien, a partir de lo anterior y conforme al artículo 35 de la ley 1826 de 2017 (ley 1826, 2017, art. 35), se hace necesario advertir que la Fiscalía no podrá descargarse totalmente de los casos en los que se autorice la conversión de la acción penal pues deberá, en todo caso, organizarse para colaborar en la ejecución de actos de investigación complejos ${ }^{23}$. Advertido esto, no puede perderse de vista que la Fiscalía General de la Nación, al no ser parte en estos casos, debería actuar con un grado superlativo de objetividad en lo atinente a la ejecución de actos complejos.

Ahora bien, en nuestra opinión, el punto problemático de esta regulación radica en las posibles interpretaciones sistemáticas a las que pueden dar lugar los enunciados normativos objeto de estudio. Pensamos que principalmente son tres:

En primer lugar, la regla general es que el acusador privado puede realizar los mismos actos de investigación para los cuales está facultada la defensa pero, excepcionalmente y atendiendo a la proporcionalidad, puede solicitar ante el juez de control de garantías la realización de actos complejos que, en todo caso, ejecutará la Fiscalía y se someterán al control posterior del juez de control de garantías. El acusado, por su parte, no podrá solicitar la realización de actos complejos ante el juez mencionado.

Lo importante, de cara a esta primera interpretación es que el acto complejo de investigación se presenta como una excepción y que no podría solicitarse por parte de la defensa. Así, la facultad excepcional del acusador privado que le permite solicitarle a la Fiscalía, previa autorización del juez, la realización de actos de investigación complejos se deriva del ejercicio de

23 Además, no puede perderse de vista que es posible que se presente una causal de reversión de la conversión, lo que implicaría un desgaste adicional para la Fiscalía General de la Nación. 
la acción penal, pues es este ejercicio el que justifica la intervención, así sea indirecta, de derechos fundamentales.

Para sustentar lo anterior, podrá decirse que en el acusador privado subsiste una de las razones que le permitían a la Fiscalía el realizar todos los actos de investigación previstos por nuestro legislador: el acusador privado desarrolla, en los casos en los que resulta procedente la conversión de la acción penal, la función de acusación y, en consecuencia, asume la carga de demostrar la responsabilidad penal del procesado más allá de toda duda razonable.

Y si esa intervención de derechos o garantías fundamentales tiene el carácter de excepcional, lo que no ocurre cuando la acción es ejercida por la Fiscalía General de la Nación, ello se debe precisamente a que el acusador privado no se guía por el mismo criterio de objetividad que guía al ente público acusador. En consecuencia, atendiendo al interés particular que representa el acusador privado, se justifica la reducción de las facultades de investigación de este, cuando funge como parte acusadora.

Por su parte, la defensa al no tener la función de acusar y al no guiar su investigación por criterios de objetividad, tendría vedado el solicitar la realización de actos de investigación complejos. A ello habría que sumarle que, al estar cobijado el procesado por la presunción de inocencia, en principio, la defensa no asume la carga de probar y, en consecuencia, nuestro legislador, incluso con la entrada en vigencia de la ley 1826 de 2017 (ley 1826, 2017), mantiene restringidas sus facultades investigativas a las previstas por los artículos 267 y siguientes del Código de Procedimiento Penal (Código de Procedimiento Penal, 2004, art. 267).

Si se asume esta primera interpretación, se hace necesario concluir que la ley 1826 de 2017 (ley 1826, 2017) mantiene un desequilibrio entre las partes procesales, en conformidad con los actos de investigación, aun cuando limita en gran medida las facultades de la parte acusadora, en los casos en los que nos encontramos frente al acusador privado.

En segundo lugar, el acusador privado puede solicitar la realización de actos complejos como regla general, además, podrá realizar aquellos actos para los que está facultada la defensa. Para sustentar esta interpretación, habría que entender que el acusador privado reemplaza en todo a la Fiscalía y que, por lo mismo, adquiere idénticas facultades de investigación a las de esta. 
Desde nuestro punto de vista, la interpretación no resulta acertada, al considerar la redacción del artículo 35 de la ley 1826 de 2017 (ley 1826 de 2017) como excepción a la regla general, esta redacción contempla el que el acusador privado pueda solicitar la realización de actos complejos.

Sin embargo, nos parece necesario incluir esta interpretación, para señalar que es contraria al sentido de los artículos 34 y 35 de la ley 1826 de 2017 (ley 1826, 2017, art. 34 y 35) y que, por lo mismo, no podemos permitir que en la práctica los actos de investigación complejos solicitados por el acusador privado se conviertan en la regla general.

Así las cosas, se hace necesario desechar esta interpretación desde el plano teórico, para garantizar que la misma no se convierta en una realidad práctica.

En tercer lugar, si el acusador privado y la defensa tienen las mismas facultades investigativas y el acusador privado puede solicitar la realización de actos de investigación complejos, la defensa también se encuentra facultada para ello.

El acusador privado y el acusado parten de un plano de igualdad: ambas partes tienen, en principio, las mismas facultades investigativas, que son las que se encuentran consagradas en los artículos 267 al 274 del Código de Procedimiento Penal (Código de Procedimiento Penal, 2004, art. 267-274) pero, adicionalmente, para esta interpretación los actos complejos pueden ser solicitados por cualquiera de las partes, esto es, por el acusador privado y por la defensa. Con esto se generaría un equilibrio real en materia de actos de investigación, que no existe en principio entre la Fiscalía y el acusado.

Dicho equilibrio se explicaría en atención a que tanto el acusador privado como el acusado representan un interés particular: el primero representa el interés de la víctima y el segundo representa el interés del procesado. Y sería esta la razón para, en primer lugar, exigir los controles previo y posterior por parte del juez de control de garantías. En segundo lugar, para impedir que tanto el acusador privado como el acusado ejecuten los actos de investigación, encargando a la Fiscalía General de la Nación dicha tarea.

En consecuencia, el acto de investigación lo ejecutará la Fiscalía General de la Nación que, aun cuando conserva la titularidad de la acción penal, no es parte en estricto sentido, en nuestro sentir, esto la dota de un mayor grado de objetividad. Por lo dicho y en desarrollo de los principios de igualdad de 
armas y de objetividad, pensamos que la Fiscalía General de la Nación les debe entregar los resultados del acto investigativo a ambas partes: acusador privado y acusado.

Para sustentar la viabilidad de esta interpretación, debe tenerse en cuenta, además de lo dicho, que si bien la defensa no acusa sino que se defiende precisamente de la acusación, esta sigue siendo una parte procesal que estructura su propia teoría del caso; que puede orientarse hacia una defensa afirmativa que va a implicar el que la defensa investigue, obtenga elementos cognoscitivos, los someta a cadena de custodia y pruebe en juicio. En consecuencia, no podemos estancarnos en ese lugar común donde se nos dice que en el proceso penal la defensa no tiene la carga de la prueba. Su actividad puede ser proactiva y esa proactividad se puede ver limitada con el trato diferencial que existe entre defensa y parte acusadora en materia de actos investigativos, máxime cuando ambas representan un interés particular.

Por tanto, creemos que invocando el principio de igualdad de armas, la defensa podría solicitar, de manera excepcional, la realización de actos complejos por parte de la Fiscalía General de la Nación, que ya no es su contraparte y debe actuar con una objetividad total, siempre que medie control previo del juez de control de garantías y los resultados del acto investigativo se sometan al control de un juez de la misma naturaleza. Adicionalmente, insistimos en que esos resultados se le deberían entregar a ambas partes: acusador privado y acusado.

Ahora bien, no es tarea fácil determinar, de manera ex ante, cuándo se le hace necesario a la parte acusada solicitar la realización de actos complejos. Sin embargo, pensamos en las siguientes hipótesis:

- En los casos de defensa afirmativa ${ }^{24}$ : cuando el acusado pretende probar causales que excluyen la antijuridicidad o la culpabilidad (Código Penal, 2000, art. 32). Incluso, puede pensarse en algunas causales de atipicidad objetiva por la ausencia de imputación, como es el caso de la auto-puesta en peligro de la víctima ${ }^{25}$.

\footnotetext{
24 Sobre defensa alternativa o afirmativa puede consultarse a Guzmán ( 2019).

25 Para demostrar que la víctima contribuyó en la creación del riesgo jurídicamente desaprobado, puede que haga falta investigar a la víctima, interviniendo derechos o garantías fundamentales, siempre que ello resulte proporcional y debiendo la defensa exponer los motivos fundados que indican la necesidad de realizar el acto investigativo complejo.
} 
- En los casos en los que el acusado cuente con motivos fundados que indiquen que se está presentando una de las causales que dan lugar a la reversión de la acción penal, de conformidad con el artículo $38^{26}$ de la ley 1826 de 2017 (ley 1826, 2017, art. 38), sobre todo en lo relativo a los actos de desviación de poder que pueden presentarse por parte del acusador privado.

- Cuando el acto de investigación complejo resulte necesario para el acusado, pues serán sus resultados la única forma de determinar la inocencia del procesado.

Obviamente, no pretendemos prever todos los casos en los que un acto de investigación complejo resultaría necesario para el acusado; pero creemos que los eventos propuestos son ilustrativos sobre el punto que queremos dejar anotado.

Pues bien, con esta interpretación que proponemos podría responderse de manera afirmativa a la pregunta que nos planteamos al inicio del texto.

\section{Conclusión}

Con nuestro trabajo hemos analizado la figura del acusador privado a la luz del principio de igualdad de armas que orienta nuestro sistema acusatorio. En particular, nos hemos centrado en los actos de investigación que puede realizar el acusador privado, para luego proponer distintas interpretaciones sobre los enunciados normativos contenidos en los artículos 34 y 35 de la ley de marras (ley1826, 2017).

Sin pretender imponer nuestro pensamiento, hemos propuesto una interpretación en nuestra opinión viable que le permitiría realizar, de manera excepcional, tanto al acusador privado como al acusado, actos de investigación complejos. Actos que serían ejecutados, en todo caso, por la Fiscalía General de la Nación y que sólo serán autorizados por el juez de control de garantías cuando existan motivos fundados que los soporten y cuando resulten proporcionales.

26 “Artículo 560. Reversión. En cualquier momento de la actuación, de oficio o por solicitud de parte, el fiscal que autorizó la conversión podrá ordenar que la acción privada vuelva a ser pública y desplazar en el ejercicio de la acción penal al acusador privado cuando sobrevenga alguna de las circunstancias descritas en el artículo 554. En este evento, el fiscal retomará la actuación en la etapa procesal en que se encuentre" (ley 1826, 2017). 
Los resultados de dichos actos investigativos se someterán al control posterior del juez de control de garantías y se le entregarán a ambas partes procesales.

Con esta interpretación que proponemos se podría concluir que la ley 1826 de 2017 (ley 1826, 2017) ha contribuido, en gran medida, al principio de igualdad de armas, en un escenario en el que se ven enfrentados dos intereses particulares.

Lo que se quería, en todo caso, era contribuir en el debate sobre una figura novedosa como lo es el acusador privado y problematizar sobre la misma.

\section{Referencias bibliográficas}

Angel Londoño, J. (2017). Los Actos de Investigación Del Acusador Privado en Colombia. En: C. A. Diaz. Acusación Privada y Sistema Acusatorio (pp. 115-159). Ediciones Nueva Jurídica.

Baytelman A., A. y Duce J., M. (2011). Litigación Penal Juicio Oral y Prueba. Grupo Editorial Ibañez.

Bernal Cuéllar, J. y Montealegre Lynett, E. (2013). El Proceso Penal Estructura y Garantías Procesales. Universidad Externado de Colombia.

Binder, A. M. (2016). Introducción al derecho procesal penal. Ad-Hoc.

Calamandrei, P. (1973a). Instituciones de Derecho Procesal Civil (Vol. I). (S. S. Melendo, Trad.). Ediciones Jurídicas Europa-América.

Calamandrei, P. (1973b). Instituciones de Derecho Procesal Civil (Vol. II). (S. S. Melendo, Trad.). Ediciones Jurídicas Europa-América.

Carnelutti, F. (1971). Principios del proceso penal. (S. S. Melendo, Trad.). Ediciones Jurídicas Europa-América.

Carnelutti, F. (2007). Cómo se hace un proceso. Temis S.A.

Cassese, A. (2008). International Criminal Law. Oxford University Press.

Dei Malatesta, N. F. (1964). Lógica de las pruebas en materia criminal. Temis.

Guzmán Díaz, C. A. (2017). Acusación Privada Análisis de la ley 1826 de 2016. En: C. A. Díaz, Acusación Privada y Sistema Acusatorio (pp. 191-223). Ediciones Nueva Jurídica.

Guzmán Díaz, C. A. (2019). La carga dinámica de la prueba en el delito de lavado de activos. Análisis crítico a la posición jurisprudencial en Colombia. En: C. A. Guzmán Díaz, C. Viveiros y J. E. Carrión Díaz, El Delito de Lavado de Activos. Aspectos de Política Criminal, Dogmáticos y Probatorios (pp. 451-486). Grupo Editorial Ibáñez.

Hassemer, W. (1999). Persona, Mundo y Responsabilidad. Temis S.A.

Matusan Acuña, C. (2013). La Acción Penal Privada y la afectación de derechos fundamentales. Revista Via luris, (14), 187-197. 
Molina Galindo, L. M. (2018). Una reflexión sobre el nuevo procedimiento penal abreviado y el acusador privado. Verba luris, 39, 107-122.

Montero Aroca, J., Gómez Colomer, J. L., Montón Redondo, A. y Barona Vilar, S. (2003). Derecho Jurisdiccional I (12 ed.). Tirant Lo Blanch.

Nación, F. G. (2017). Manual Nuevo Procedimiento Penal Abreviado y Acusador Privado. Fiscalía General de la Nación.

Saray Botero, N. (2017). Procedimiento Penal Acusatorio. Leyer Editores.

Silva Sánchez, J. M. (2011). La expansión del Derecho penal. IB de F.

Taruffo, M. (2006). Ideas para una teoría de la decisión justa. En: M. Taruffo, Sobre las fronteras. Escritos sobre la justicia civil. (B. Quintero, Trad.). Temis.

Vivares Porras, L. F. (2017). Perspectivismo y derecho. Articulación del concepto orteguiano de verdad con las formas cognoscitivas de la experiencia jurídica actual. Universidad Pontificia Bolivariana.

\section{Referencias legales y jurisprudenciales:}

Colombia, Asamblea Constituyente, Constitución Política de Colombia del 20 de julio de (1991), segunda edición corregida, Bogotá.

Colombia, Congreso de la República (2000), Código de Procedimiento Penal, Ley 600 del 24 de julio del año 2000, Bogotá.

Colombia, Congreso de la República (2004), Código de Procedimiento Penal, Ley 906 del 1 de septiembre del año 2004, Bogotá-

Colombia, Congreso de la República (2011), Acto legislativo 06 del 24 de noviembre del año 2011, Bogotá.

Colombia, Congreso de la República (2017), Ley 1826 del 12 de enero de 2017, Bogotá.

Corte Constitucional (2007).Bogotá, sentencia C-209 de 2007, Magistrado Ponente: Manuel José Cepeda Espinosa.

Corte Constitucional (2008). Bogotá, sentencia C-186 de 2008, Magistrado Ponente: Nilson Pinilla Pinilla.

Corte Constitucional (2011). Bogotá, sentencia C-127 de 2011, Magistrado Ponente: Maria Victoria Calle Correa.

Corte Constitucional (2014). Bogotá, sentencia C-616 de 2014, Magistrado Ponente: Jorge Ignacio Pretelt Chaljub.

Corte Constitucional (2018). Bogotá, sentencia C-016 de 2018, Magistrado Ponente: Diana Fajardo Rivera.

Corte Constitucional (2019). Bogotá, sentencia C-225 de 2019, Magistrado Ponente: Antonio José Lizarazo Ocampo.

Sala de Casación Penal, Corte Suprema de Justicia (2016). Bogotá, sentencia con radicado 45790 del 27 de enero de 2016, Magistrado Ponente: Gustavo Enrique Malo Fernández.

Sala de Casación Penal de la Corte Suprema de Justicia (2017).Bogotá, sentencia de tutela STP6135-2017 del 3 de mayo de 2017, Magistrado Ponente: Patricia Salazar Cuéllar. 